\title{
Can industry be wooed back into the act?
}

There is a cruel irony in the fact that, just as the explosion of parasite resistance to drugs makes it more pressing than ever to find new drugs and vaccines, the pharmaceutical industry is abandoning malaria research.

Tropical disease research has been a major casualty of the consolidation of the industry over the past decade, with companies tending to concentrate their resources on fewer and potentially more profitable - areas. Malaria research was shed, for example, in the merger between Rhône-Poulenc Santé and Rorer in 1990, with the new company RhônePoulenc Rorer focusing on just six therapeutic areas.

The number of companies carrying out research on malaria vaccines can now be counted on the fingers of one hand. And industry has virtually abandoned drug discovery - the only company still pursuing such research, Hoffmann-La Roche, says that it too has now decided to stop.

Companies are restricting their activity to the clinical development of those compounds that are known to work. "It's cheaper; we start with a molecule that works," says one industrialist. "It's development, not research."

Many companies have had their fingers burned. Over the past few decades, for example, several of them screened hundreds of thousands of compounds without much success. But Pierre Druihle, a researcher at the Institut Pasteur in Paris, argues that it is ironic that companies should abandon drug discovery just when assays for screening for active drug compounds are much more sensitive than in the past, and when genome research and molecular studies are yielding new targets for rational drug design.

A fund has now been created to support a proposed collaborative programme to sequence the 30-megabase genome of $P$. falciparum. The US Department of Defense has given $\$ 15$ million to the fund, with another $\$ 4$ million coming from the US Burroughs-Wellcome Fund, the UK Wellcome Trust and NIH. Pilot studies are being carried out by the Institute for Genome Research in Rockville, Maryland, Britain's Sanger centre, and NIAID.

It is urgent to relaunch drug discovery, says Dyann Wirth, a molecular parasitologist at Harvard School of Public Health, and chair of WHO's committee on malaria drugs. But without industry, drug development is a lost cause, says Druihle, as only it has the capacity to synthesise and test the hundreds of analogues needed to convert a promising molecule into a drug lead.

\section{Vaccines await 'breakthrough'}

The picture for vaccine scientists is less bleak, but only marginally so. The large vaccine manufacturers, SmithKline Beecham and

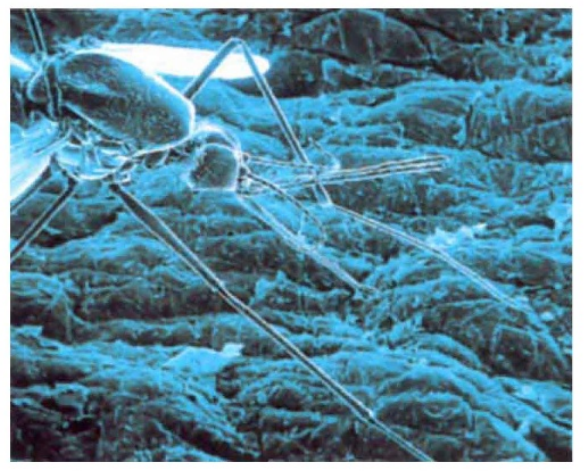

Once bitten: most companies have abandoned their attempts at drug discovery.

Pasteur Meriéux Connaught, still work on malaria vaccines, but many others, such as Merck, Sanofi, and Behringwerke, have given up.

Companies are traditionally reluctant to invest in vaccine development, which carries high costs, low profits and big risks of liability claims. But many companies say that whereas basic research is now producing interesting leads, it has not progressed sufficiently, and that investing now would therefore be a costly and risky business.

The relative lack of industrial interest means that vaccine scientists often cannot produce the large quantities of good manufacturing-practice (GMP) grade antigens needed for clinical trials. "We have six or seven interesting molecules, but have to synthesize them ourselves, while we don't have the competence to work with adjuvants [compounds included in vaccine formulations, which boost the immune system]", says Luiz Pereira da Silva, a vaccine researcher at the Institut Pasteur. "We are forced to improvise, and we can't advance unless we can do trials."

\section{Relaunching industrial research}

Faced with the reality of industrial withdrawal from the field, scientists and international organizations are engaged in a flurry of discussions with industrialists to try to encourage them to change their mind.

Research agencies are contemplating strategies to fill the gap left by the retreat of companies, by going beyond their traditional role of funding basic research, and also carrying out development work to bring malaria vaccines to a stage where companies might regain interest.

The idea of creating a broad multi-disease programme to develop vaccine concepts is "under consideration" at the US National Institutes of Health, according to its director Harold Varmus. "We need to try to go as far as possible by ourselves," says Maxime Schwartz, director of the Institut Pasteur. He adds that a "major problem" in doing so in
Europe is the lack of a plant to produce GMPgrade vaccines for research. "This is too expensive for Pasteur alone."

Another idea being floated is for the World Bank and other agencies to subsidize the early stages of drug and vaccine discovery to spread the financial risk. Another is to create consortiums between drug companies, donors and public research agencies. The introduction in Europe of legislation similar to the US Orphan Drugs Tax Credits would also help, says Walter Van Der Smissen, head of government affairs at SmithKline Beecham Biologicals.

Many industrialists say they are open to the idea of taking part in consortia. But they point out that that such schemes may not be feasible, given that they are fraught with problems such as sharing of intellectual property, and are likely to fall foul of legislation banning cartels. "I have difficulty seeing how it could happen," says Van Der Smissen, "but perhaps it's time to change the model of thinking."

A more market-driven approach is to guarantee companies sales for their products. There is a precedent. The enormous size of the vaccine market in the developing world - about 3.5 billion doses annually has allowed organizations such as the United Nations children's fund, UNICEF, to purchase vaccines at cost price. Manufacturers benefit because the huge volume of orders allows them to cut their costs.

Taking the idea further, some suggest that international organizations could specify in advance the characteristics of a specific vaccine or drug which, if met, would qualify it for worldwide use. This would entice companies to invest in the development of such products, say industrialists.

But companies themselves also "need to reassess their markets", argues Richard Feachem of the World Bank. He points out that many countries in Asia and Latin America are relatively well off, while India, and even many poor African countries, have burgeoning middle classes with money to spend on healthcare.

Drug companies are beginning to acknowledge that most of their sales growth over the next ten to twenty years will come from developing countries. "Glaxo-Wellcome and others will put greater emphasis on developing countries and this will lead to renewed interest in meeting local country needs," says one company official.

Growth in these markets will eventually stimulate drug companies to reinvest in tropical disease research. But, until such market forces come into play, companies are unlikely to restart tropical disease research unless the international community provides them with the incentives to do so. 